\title{
Experimental investigation on puffing and micro-explosion occurrence of water in rapeseed oil emulsions droplets. Effect of the surfactant concentration.
}

\author{
Eliezer Ahmed Melo-Espinosa*1, Jérôme Bellettre ${ }^{2}$, Dominique Tarlet², Ramón Piloto- \\ Rodríguez ${ }^{1}$ and Sebastian Verhelst ${ }^{3}$
}

${ }^{1}$ Center for the Study of Renewable Energy Technologies, Faculty of Mechanical Engineering, Instituto Superior Politécnico “José Antonio Echeverría”(CUJAE), Marianao, 19390, Habana (Cuba)

2 Laboratoire de Thermique et Energie de Nantes, LTEN UMR CNRS 6607, BP 50609, 1 rue Christian Pauc, 44306 Nantes cedex 3, France

${ }^{3}$ Department of Flow, Hot and Combustion Mechanics, Faculty of Engineering and Architecture, Ghent University, Sint-Pietersnieuwstraat 41, B-9000, Ghent (Belgium)

\author{
*Corresponding author: emelo@ceter.cujae.edu.cu and \\ eliezer.ahmed.melo.espinosa@gmail.com
}

\begin{abstract}
In this paper, the assessment of puffing and micro-explosion occurrence in emulsion drops with different water percentage is studied. The emulsified fuels are formulated using micro channel emulsifier, rapeseed oil and diesel fuel as continuous phase, as well as water and Sorbitan Sesquioleate as surfactant. The formulated dispersed systems are covered under different experimental factors such as water ratio and surfactant percentage. The puffing occurrence is reported in all emulsified fuels tested (i.e. with and without surfactant). A sudden puffing and highest number of occurrence is noted when the water amount increases in all emulsified fuels. The micro-explosion phenomenon is only noted in emulsified fuel formulated without surfactant.
\end{abstract}

Keywords

Micro-explosion, puffing, Leidenfrost effect, rapeseed oil, diesel fuel

\section{Introduction}

The direct use of vegetable oils in diesel engines causes several problems such as a less efficient combustion process due to the poor atomization process and changes in the ignition delay. For these reasons and seeking for a more engine-friendly fuel, it is necessary to change the feedstock properties applying different methods such as: preheating, blending with diesel fuel, transesterification, cracking / pyrolysis or emulsification. The advantage and drawbacks of each method have been pointed out in different researches [1, 2].

Among these methods, the emulsification has an additional advantage linked to its capacity to decrease diesel engine exhaust emissions such as nitric oxides, solid and carbonaceous residues [3]. It is a cheaper method because modifications of the original engine design, special and sophisticated equipments are not necessary. The preparation of an emulsion involves no complex chemical reactions [4]. It also produces no by-products unlike transesterification [4].

According to Tran et al. [5] the combustion of emulsified fuel droplets is largely characterized by this difference between water and fuel volatility. The droplet is heated by convective and radiative heat transfer and its temperature reaches the superheat limit. Inside the droplet, this is followed by a rapid bubble nucleation, and then, internal formation of vapor bubbles [5]. The vaporization of water then blows up the oil layer and thereby forms smaller oil droplets, which increases the oil droplet's surface to volume ratio [6]. This phenomenon is called "micro-explosion" [6, 7].

The micro-explosion causes the secondary atomization which forms the bulk of much finer droplets [5]. Such secondary drops evaporate very quickly and are dispersed over a large volume, improving fuel/air 
mixing and the overall combustion efficiency [8]. This mechanism is fundamental in reducing particulate emission in the combustion of medium and heavy oils [8]. In addition, the presence of water influences the physics and chemical kinetics of combustion and has a beneficial effect on the rate-of-heat release and the reduction of pollutant emissions [9].

On the other hand, during combustion, the vaporized water reduces the flame temperature, changes the chemical composition of the reactants, resulting in higher $\mathrm{OH}$ radical concentration controlling the $\mathrm{NO}$ formation rate and soot oxidation, and dilutes the rich zones in the combustion chamber [9]. In addition, due to the micro-explosion phenomenon as a consequence of the dispersed water into emulsified fuel, it is also possible to improve the atomization process and recover the combustion efficiency when it is used as diesel engine fuel. However, it is important to point out that the physicochemical properties of emulsified fuel play a decisive role.

Nevertheless, a large scientific effort has been devoted to the experimental evaluation of the microexplosion phenomenon [10-26]. However, the micro-explosion phenomenon has been also questioned [27]. Califano et al. [8] pointed out that the micro-explosion does not always occur, and that its occurrence depends on a number of parameters. An important factor affecting the micro-explosion could be the coalescence or phase separation of the dispersed water droplets into the continuous phase $[8,10]$.

On the other hand, several studies [11,14-16, 28-31] reported the occurrence of a particular phenomenon (i.e. puffing or bubbling) prior to micro-explosion phenomenon. The occurrence of puffing is also linked to the thermal effect of dispersed phase into continuous phase under intense heat flux. This phenomenon is not always observable, consists in the formation of irregular bubble of steam that perturbs the free surface of the droplet $[16,32]$.

In spite of the fact that puffing and micro-explosion phenomenon are well-known, discovered in 1965 by Ivanov and Nefedov [29] and defined separately by Watanabe et al. [32], their assessment involving emulsified fuels have not been studied thoroughly. For this reason, the scope of this investigation is to analyze the puffing and micro-explosion occurrence in emulsified fuels obtained through a micro-channel emulsifier.

\section{Experimental set-up and procedures}

The experimental investigation of puffing and micro-explosion occurrence is conducted in emulsified fuel drops on a hot surface. The emulsion fuel drops are placed on a heated plate leading to the Leidenfrost effect. Recently, several researches have been conducted in this topic using Leidenfrost burning [11, 1416, 22].

A pipettor VWR with tip ejector (volume: $2-20 \mu \mathrm{L}$, precision: $\leq 1.5-0.3 \%$ and accuracy of $\pm 1.0-0.6 \%$ ) is used as a fuel droplet generator. Additional equipment such as a high-speed camera model $675 \mathrm{~K}-\mathrm{M} 1$ (HighSpeedStar series) provided by LaVision, a hot plate controlled by a power station Weller and a Type$\mathrm{K}$ thermocouple coupled to a K-Thermocouple thermometer Hanna are used for the visualization and control of the studied phenomena. The schematic diagram of the experimental setup used is shown in Figure 1.

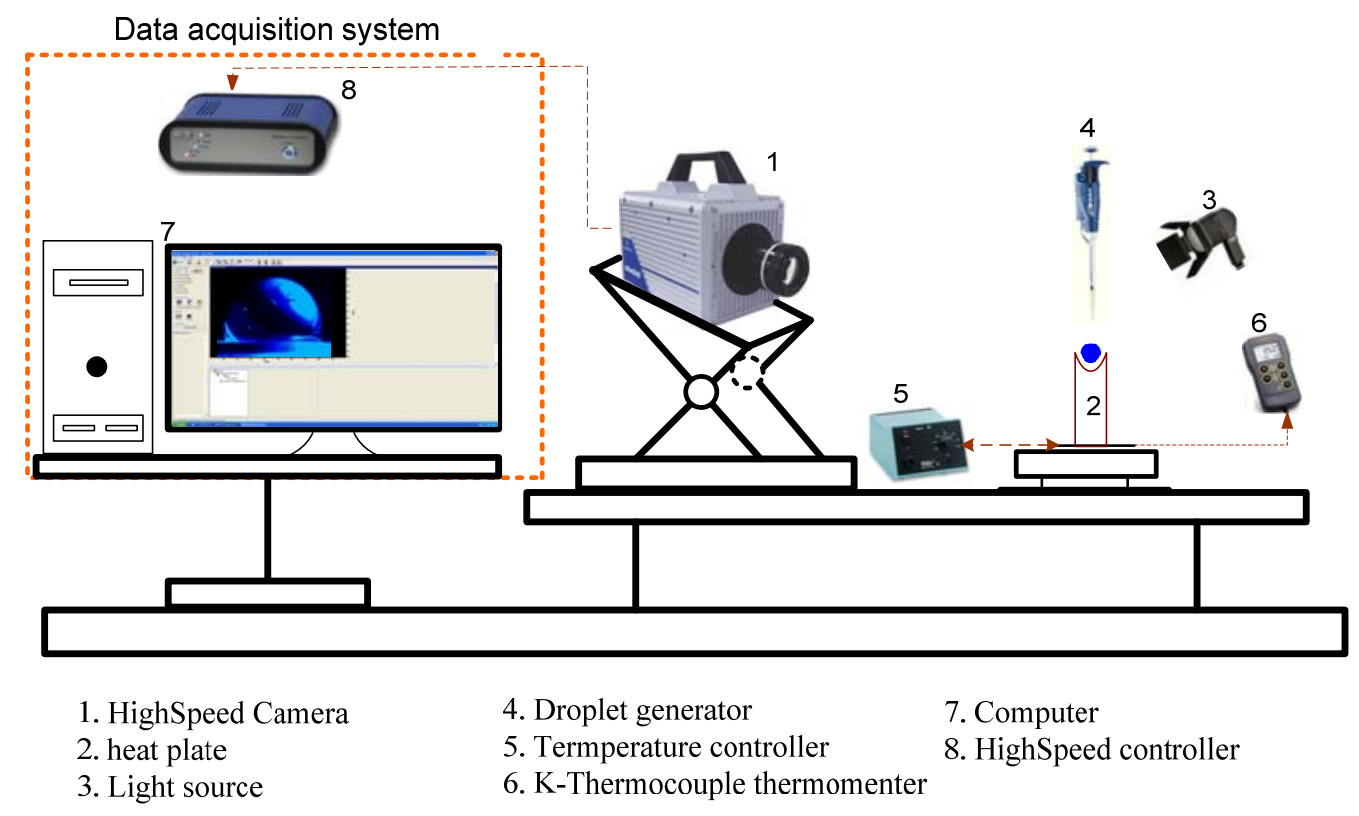

Figure 1. Schematic diagram of the micro-explosion setup 
The assessment of the puffing and micro-explosion occurrence is conducted under selected test conditions keeping fixed the hot plate temperature at $365^{\circ} \mathrm{C}$ and atmospheric pressure. This temperature was found as a proper value to ensure the Leidenfrost effect occurrence (emulsified droplet lifted) avoiding the quick warm-ups and vaporization, in agreement with previous experiments developed by Mura et al. [33] and Tarlet et al. [13, 15]. The test conditions are shown in Table 1.

Table 1. Puffing and micro-explosion test conditions

\begin{tabular}{c|ccc}
\hline $\begin{array}{c}\text { Hot plate } \\
\text { temperature } \\
\left({ }^{\circ} \mathrm{C}\right)\end{array}$ & $\begin{array}{c}\text { Droplet } \\
\text { volume }(\mu \mathrm{L})\end{array}$ & $\begin{array}{c}\text { Droplet } \\
\text { diameter } \\
(\mathrm{mm})\end{array}$ & $\begin{array}{c}\text { Acquisition } \\
\text { frequency } \\
(\mathrm{Hz})\end{array}$ \\
\hline \hline 365 & 12 & 2.84 & 750
\end{tabular}

In this study several emulsified fuels are prepared based on previous results reported in [35]. The materials used are rapeseed oil and diesel fuel as continuous phase, water as dispersed phase and Sorbitan Sesquioleate as surfactant. The emulsified fuels studied here are ERO7, ERO8, ERO9, ERO10, ERO11 and ERO12, which are prepared through a micro-channel emulsifier. The continuous phase and surfactant were previously blended and stirred during 15 minutes (at $1000 \mathrm{rpm}$ ) as a first step before the use of micro-channel emulsifier. The experimental facilities used for the emulsification process were three piston displacement pumps (ARMEN-AP-TRIX-500-200) feeding a micro-channel with an optimized geometry, which has been recently presented in details by Belkadi et al. [35].

The emulsions' composition and properties are shown in Table 2. Moreover, additional emulsified fuels are formulated avoiding the use of any surfactant and keeping fixed the water ratio $(10 \%, 20 \%$ and $30 \%)$. The aim of this proposal is to analyze the effect of surfactant and dispersed phase concentration on puffing and micro-explosion occurrence. That is why the most stable and the less stable emulsions are going to be compared.

Table 2. Composition and properties of the emulsified fuels - ERO: Emulsified rapeseed oil, ${ }^{*}$ RO-Diesel: Blend of $20 \%$ of rapeseed oil-in $80 \%$ of diesel fuel

\begin{tabular}{c|ccccc}
\hline \hline $\begin{array}{c}\text { Emulsified } \\
\text { fuel }\end{array}$ & \multicolumn{3}{|c}{ Composition } & \multicolumn{2}{c}{ Properties } \\
\hline & $\begin{array}{c}\text { RO-Diesel } \\
(\% \text { Vol. })\end{array}$ & $\begin{array}{c}\text { Surfactant }(\% \\
\text { Vol. })\end{array}$ & $\begin{array}{c}\text { Water } \\
(\% \text { Vol. })\end{array}$ & $\begin{array}{c}\text { Dynamic } \\
\text { viscosity } \\
(\mathrm{mPa} . \mathrm{s})\end{array}$ & $\begin{array}{c}\text { Average } \\
\text { droplet } \\
\text { size }(\mu \mathrm{m})\end{array}$ \\
\hline \hline ERO7 & 88 & 2 & 10 & 4.6 & 4.97 \\
ERO8 & 78 & 2 & 20 & 16.1 & 8.12 \\
ERO9 & 68 & 2 & 30 & 20.4 & 9.2 \\
ERO10 & 86 & 4 & 10 & 5 & 4.88 \\
ERO11 & 76 & 4 & 20 & 16.5 & 7.96 \\
ERO12 & 66 & 4 & 30 & 21 & 8.89
\end{tabular}

\section{Experimental results}

The emulsified droplets undergo a Leidenfrost effect as a result of the heat flux on the dispersed water within emulsions. Under this effect, a continuous process of vapor bubbles formation within emulsified fuel matrix is expected. For this reason, this section focuses on effect of dispersed water quantity into emulsified droplets exploring vapor bubble growth itself. The vapor bubble growth in the emulsified droplets was studied in a data set of captured images prior the first puffing or micro-explosion occurs. The time lapse in the vapor bubble formation and growth are shown in Fig 2. In general, an increase of surfactant percentage in the emulsions leads to a disruptive effect on vapor bubble formation and its further development.

The time lapse between generating droplet on the hot surface and vapor bubble formation varies significantly from an emulsion to another depending of their composition. For each set, bigger vapor bubbles are observed in a shorter period of time for emulsions without surfactant.

In this regard, comparable results have been attained for other emulsified fuels [10-12], in spite of the effect of additional factors such as the surfactant percentage, the analyzed size of the emulsion droplet and characteristics of continuous phase (e.g. volatility, viscosity, carbon-chain length, etc.) have not been studied thoroughly. The vapor bubbles formations are linked to several phenomena such as nucleation, 
agglomeration, coalescence and bubbling which might lead to a further occurrence of puffing and microexplosion. Nevertheless, an analysis about the effect of surfactant on puffing and micro-explosion occurrence will be discussed in the next section.

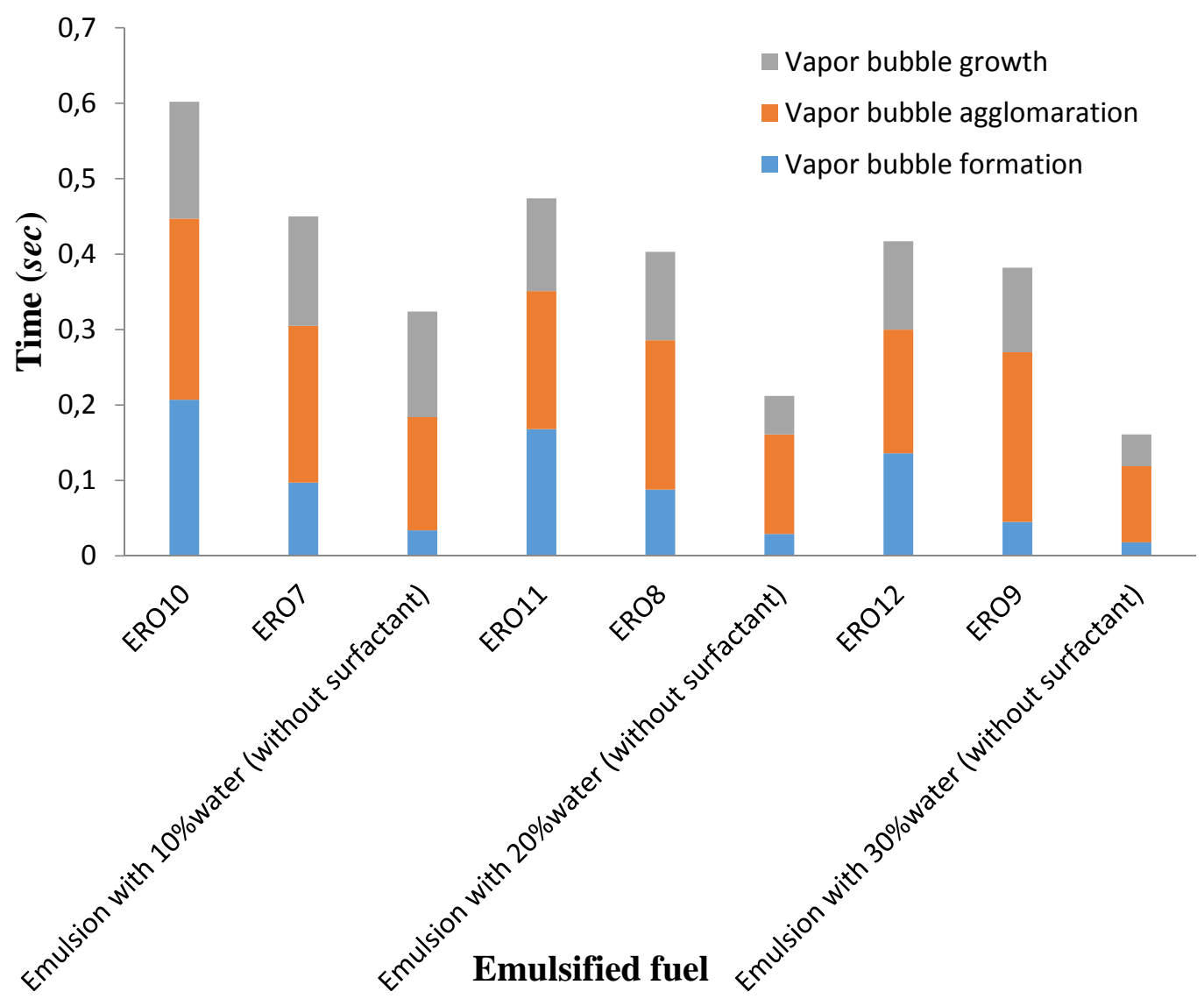

Figure 2. Time lapse between generating droplet, vapor bubble formation and growth

The experimental results of puffing and micro-explosion occurrence in the formulated emulsions with/without surfactant are shown in Fig 3 and Fig. 4. For all cases, the light luminous areas around the droplet surface represent the surrounding vaporized fuel.

As can be noted, an increase of water percentage promotes a sudden occurrence of the puffing phenomenon. The number of puffing occurrence per set of emulsions also increases with the water ratio, but contrary when the surfactant percentage is increased. A delay of puffing process with the increase of surfactant percentage was also attained. This behavior is a consequence of the surfactant activity within the interphase boundary inside the emulsified fuels.

On the other hand, the micro-explosion phenomenon only occurs in emulsified fuels formulated without surfactant (see Fig 3, Fig 4). This fact might be correlated with the sudden agglomeration and coalescence of the dispersed water in the bottom of the emulsified droplet [12], which is associated to differences between dispersed and continuous phase density. Moreover, a strong puffing process like weak microexplosion is noted in the emulsified fuel prepared with $2 \%$ of surfactant and higher water amount (i.e. ERO12, not shown here du to lake of place).

An average water droplet size of $5 \mu \mathrm{m}$ is seen as an adequate size for a good micro-explosion as shown by Mura et al. [33] and Tarlet et al. [13, 15]. However, micro-explosion phenomenon might occur also for smaller or bigger droplets size, although it may be more or less strong according to Tarlet et al. [15]. In our study, only two emulsified fuel reach this value (i.e. ERO7 and ERO10) but they do not micro-explode. This behavior might be associated with different factors such as the composition of both sets of dispersed systems (e.g. water and surfactant percentage) and physicochemical properties of continuous phase (e.g. volatility and boiling temperature). 


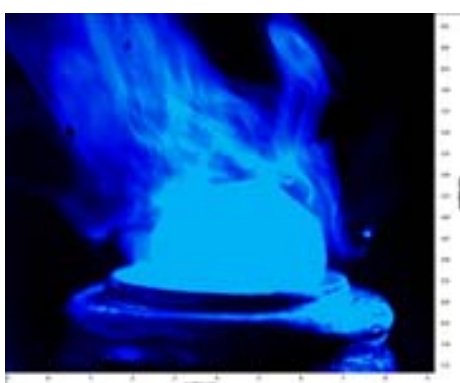

$\mathrm{t}=0 \mathrm{sec}$

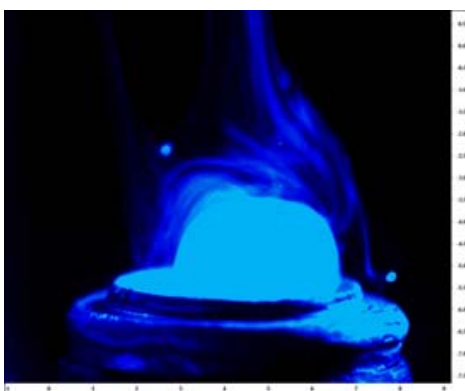

$\mathrm{t}=0$ sec

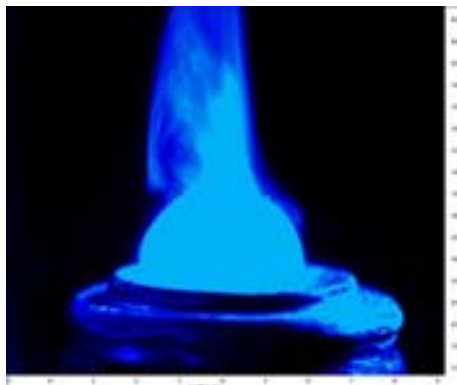

$\mathrm{t}=0 \mathrm{sec}$

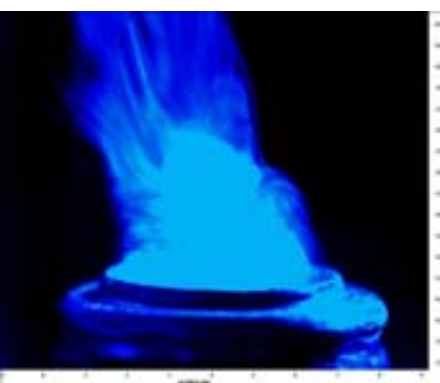

$\mathrm{t}=0.736 \mathrm{sec}$

(a)

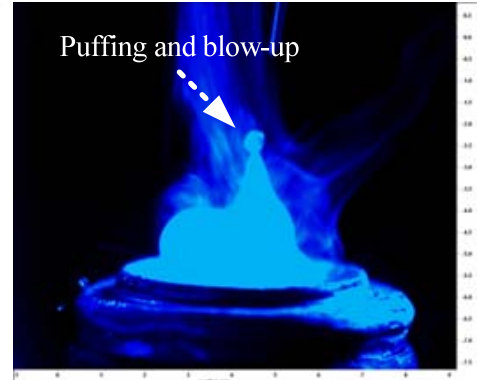

$\mathrm{t}=0.569 \mathrm{sec}$

(b)

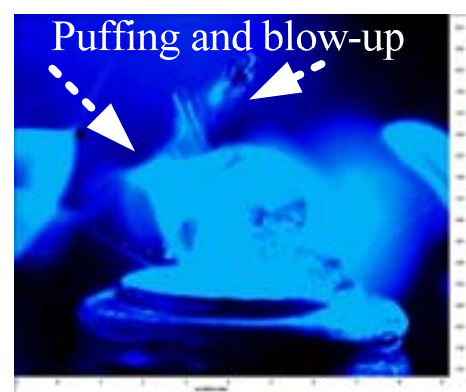

$\mathrm{t}=0.416 \mathrm{sec}$

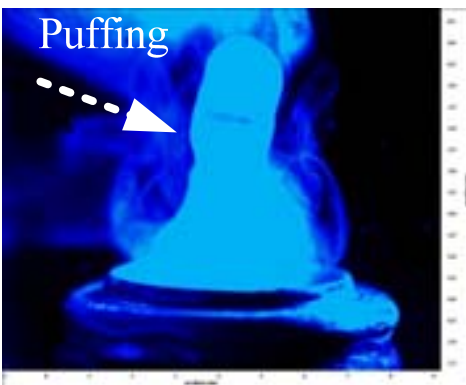

$\mathrm{t}=1.035 \mathrm{sec}$

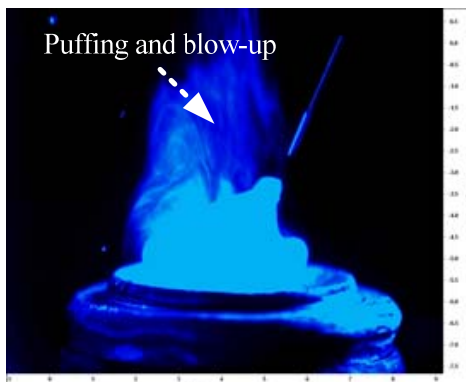

$\mathrm{t}=0.745 \mathrm{sec}$

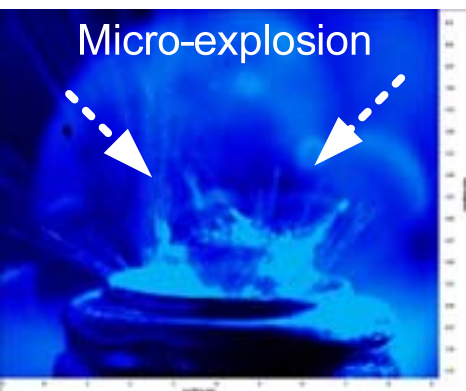

$\mathrm{t}=0.68 \mathrm{sec}$

(c)

Figure 3. Sequence of puffing and micro-explosion occurrence: a) ERO10, b) ERO7, c)Emulsified fuel prepared with90\% of diesel-rapeseed oil blend and $10 \%$ of water (without surfactant)

A summary of emulsified fuels burning droplets plotted in a ternary diagram is shown in Fig 5 . The black zone represents a zone where the puffing and micro-explosion phenomena are often reported in the literature [10-16, $18-20,22-26,32-34]$ using different continuous phases with increasing water emulsification up to $30 \%$. In our study, both phenomena took place in all emulsified fuels prepared without surfactant (see section 3.2 and Fig 5a). In addition, a set of emulsions formulated without surfactant but involving pure diesel fuel and different water ratio also reported the occurrence of puffing and micro-explosion phenomenon (i.e. see red-blue points in Fig 5a).

As it was previously mentioned, emulsified fuels prepared with surfactant reported puffing and vaporized fuel process (see yellow-blue points in Fig $5 \mathrm{~b}$ ). An additional set of emulsified fuels using surfactant were analyzed in order to broaden the investigate zone. In concordance with previous results, a puffing and vaporization process was also attained.

For each case of emulsions formulated with a blend of rapeseed oil-in diesel, an increase of the rapeseed oil ratio in the blend conducted to highest surrounding vaporized fuel. This assessment is characterized by differences between rapeseed oil and diesel fuel volatility, mainly. 


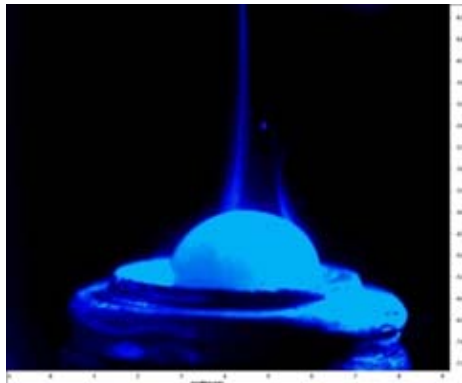

$\mathrm{t}=0 \mathrm{sec}$

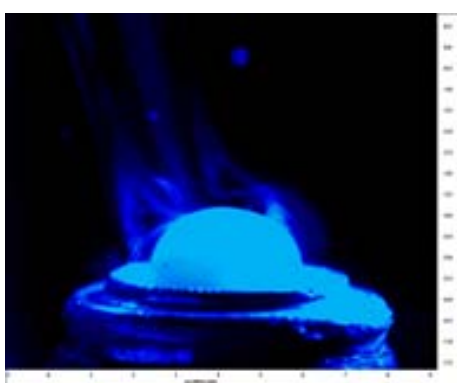

$\mathrm{t}=0 \mathrm{sec}$

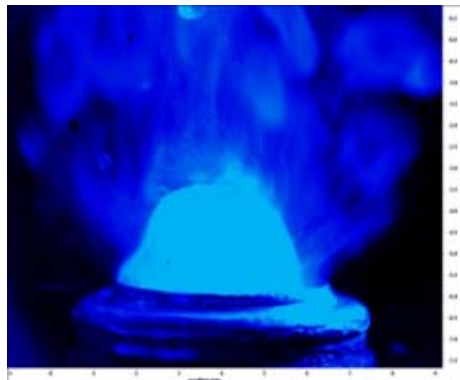

$\mathrm{t}=0 \mathrm{sec}$

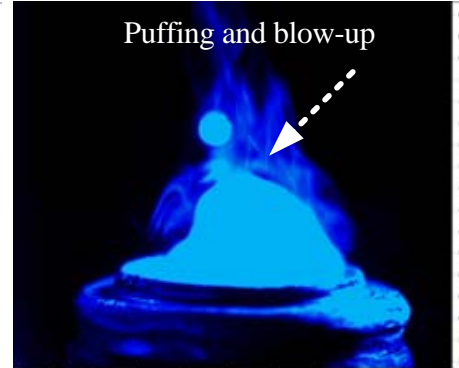

$\mathrm{t}=0.584 \mathrm{sec}$

(a)

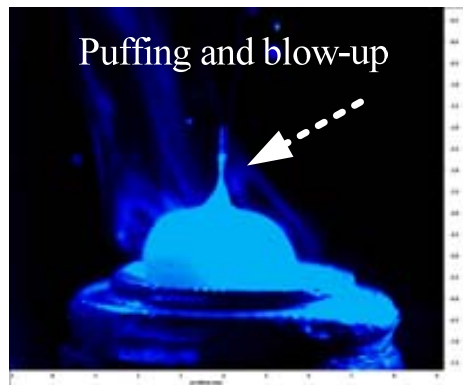

$\mathrm{t}=0.512 \mathrm{sec}$

(b)

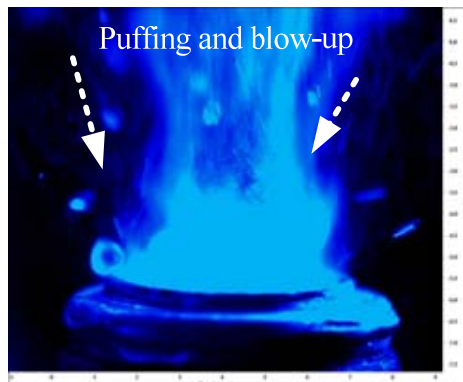

$\mathrm{t}=0.254 \mathrm{sec}$

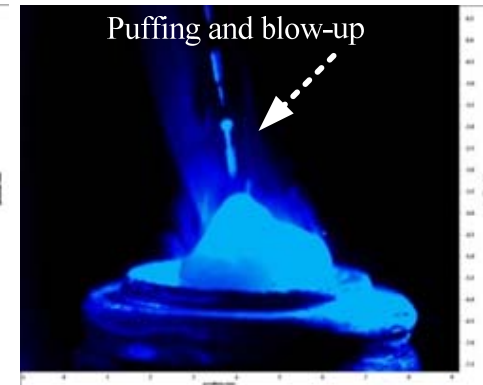

$\mathrm{t}=0.699 \mathrm{sec}$

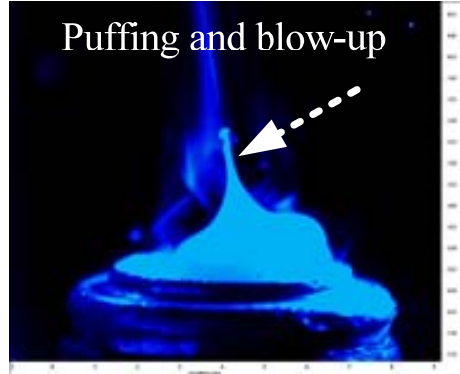

$\mathrm{t}=0.604 \mathrm{sec}$

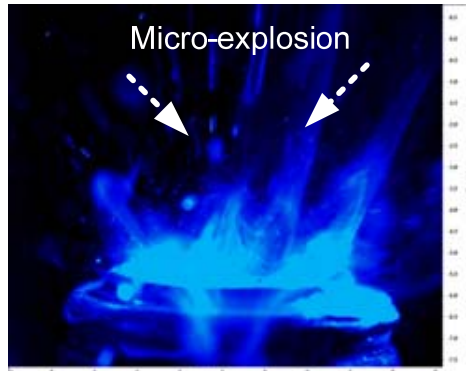

$\mathrm{t}=0.540 \mathrm{sec}$

(c)

Figure 4. Sequence of puffing and micro-explosion occurrence: a) ERO11, b) ERO8, c) Emulsified fuel prepared with $80 \%$ of diesel-rapeseed oil blend and $20 \%$ of water (without surfactant)

\section{Conclusions}

The results of several experiments varying the amount of water, surfactant and continuous phase depicted the occurrence of puffing and/or micro-explosion phenomena, even for lower water amounts. A summary of emulsified fuels burning droplets was plotted in a ternary diagram denoting an interesting zone where puffing and micro-explosion occur. A sudden puffing and highest number of occurrence is noted when the water amount was increased, but contrary when the surfactant percentage is increased. This fact is also correlated with a disruptive effect achieved on vapor bubble growth. On the other hand, the micro-explosion phenomenon only took part in emulsified fuel formulated without surfactant. All this denote that the occurrence of puffing and micro-explosion involves a multifactorial analyze based on several factors such as the dispersed water size, water amount, surfactant usage and physicochemical properties of continuous phase (e.g. volatility, boiling temperature, viscosity, carbon-chain length). 


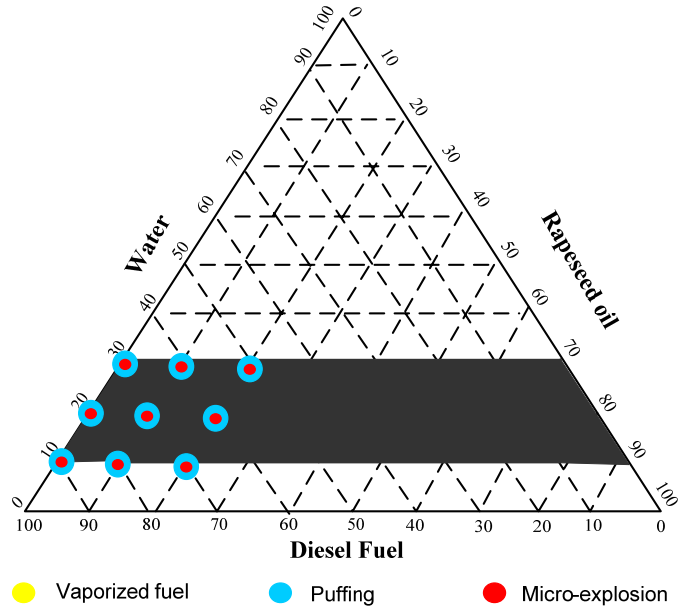

a)

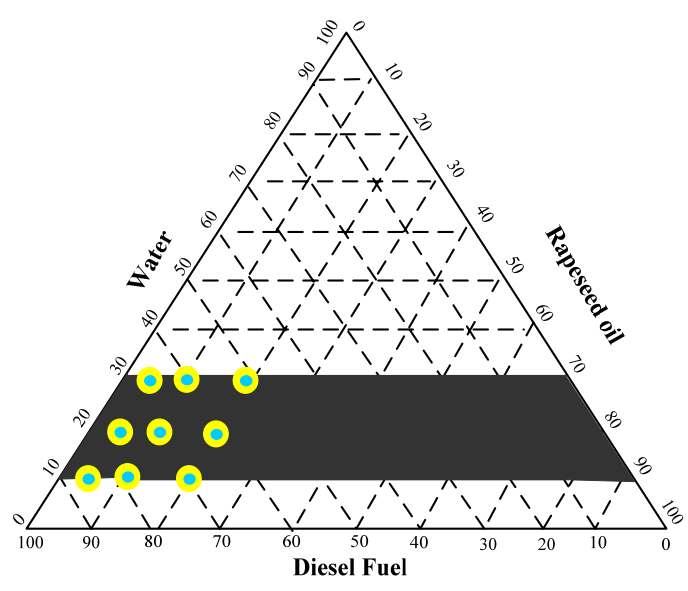

Vaporized fuel
Puffing

Micro-explosion

b)

Figure 5. Summary of emulsified fuel burning droplet plotted in a ternary diagram: a) Emulsified fuel prepared without surfactant, b) Emulsified fuel prepared with surfactant

\section{Acknowledgements}

The authors wish to express their acknowledgement to the Centre National de la Recherche Scientifique (CNRSFrance) and Flemish Interuniversity Council's (VLIR) University Development Cooperation, funding a South Initiatives Program entitled "Emulsified systems for biofuels. Assessment of their performance in diesel engines", because of their support to this research.

\section{References}

[1] M. Senthil Kumar, A. Kerihuel, J. Bellettre, and M. Tazerout, "A comparative study of different methods of using animal fat as a fuel in a compression ignition engine," Journal of Engineering for Gas Turbines and Power, vol. 128, pp. 907-914, 2006.

[2] E. Melo, R. Piloto, L. Goyos, R. Sierens, and S. Verhelst, "Emulsification of animal fats and vegetable oils for their use as a diesel engine fuel: An overview," Renewable and Sustainable Energy Reviews, vol. 47, pp. 623633, 2015.

[3] R. Ocampo-Barrera, R. Villasenora, and A. Diego-Marin, "An experimental study of the water content on combustion of heavy fuel oil/water emulsion droplets," Combustion Flame, vol. 126, pp. 1845-1855, 2001.

[4] M. Mubarak and M. Senthil Kumar, "An experimental study on waste cooking oil and its emulsions as diesel engine fuel " in Advances in Engineering, Science and Management (ICAESM), Nagapattinam, Tamil Nadu 2012, pp. $61-66$.

[5] X. Tran and I. Ghojel, "Impact of Introducing Water into the Combustion Chamber of Diesel Engines on Emissions - an Overview," in 5th Asia-Pacific Conference on Combustion,, The University of Adelaide, Adelaide, Australia, 2005, pp. 233-236.

[6] B. Debnath, N. Sahoo, and U. Saha, "Adjusting the operating characteristics to improve the performance of an emulsified palm oil methyl ester run diesel engine," Energy Conversion and Management, vol. 69, pp. 191198, 2013.

[7] R. Crookes, et al., "Systematic assessment of combustion characteristics of biofuels and emulsions with water for use as diesel engine fuels," Energy Conversion and Management, vol. 38 pp. 1785-1795, 1997.

[8] V. Califano, R. Calabria, and P. Massoli, "Experimental evaluation of the effect of emulsion stability on microexplosion phenomena for water-in-oil emulsions," Fuel vol. 117, 2014.

[9] N. Samec, B. Kegl, and R. Dibble, "Numerical and experimental study of water/oil emulsified fuel combustion in a diesel engine," Fuel, vol. 81, pp. 2035-2044, 2002.

[10] E. Mura, P. Massoli, C. Josset, K. Loubar, and J. Bellettre, "Study of the micro-explosion temperature of water in oil emulsion droplets during the Leidenfrost effect," Experimental Thermal and Fluid Science, vol. 43 pp. 63-70, 2012

[11] M. Yahaya, Z. Abdul, A. Abd, M. Heikal, and C. Crua, "Puffing and microexplosion behavior of water in pure diesel emulsion droplets during Leidenfrost effect " Combustion Science and Technology, 2016. 
[12] D. Tarlet, C. Josset, and J. Bellettre, "Comparison between unique and coalesced water drops in microexplosions scanned by differential calorimetry," International Journal of Heat and Mass Transfer vol. 95, pp. 689692, 2016

[13] D. Tarlet, C. Allouis, and J. Bellettre, "The balance between surface and kinematic energies within an optimal micro-explosion," International Journal of Thermal Sciences, vol. 107, pp. 179-184, 2016.

[14] M. Avulapati, L. Ganippa, J. Xia, and A. Megaritis, "Puffing and micro-explosion of diesel-biodiesel-ethanol blends," Fuel, vol. Fuel pp. 59-66, 2016.

[15] D. Tarlet, E. Mura, C. Josset, J. Bellettre, C. Allouis, and P. Massoli, "Distribution of thermal energy of childdroplets issued from an optimal micro-explosion," International Journal of Heat and Mass Transfer vol. $77 \mathrm{pp}$. 1043-1054, 2014.

[16] E. Mura, R. Calabria, V. Califano, P. Massoli, and J. Bellettre, "Emulsion droplet micro-explosion: Analysis of two experimental approaches," Experimental Thermal and Fluid Science vol. 56, pp. 69-74, 2014.

[17] S. Hou, F. Rizal, T. Lin, T. Yang, and H. Wan, "Microexplosion and ignition of droplets of fuel oil/bio-oil (derived from lauan wood) blends," Fuel vol. 113, pp. 31-42, 2013.

[18] H. Watanabe, Y. Suzuki, T. Harada, Y. Matsushita, H. Aoki, and T. Miura, "An experimental investigation of the breakup characteristics of secondary atomization of emulsified fuel droplet," Energy vol. 35, pp. 806-813, 2010.

[19] H. Watanabe, Y. Matsushita, H. Aoki, and T. Miura, "Numerical simulation of emulsified fuel spray combustion with puffing and micro-explosion," Combustion and Flame, vol. 157, pp. 839-852, 2010.

[20] Y. Morozumi and Y. Saito, "Effect of physical properties on microexplosion occurrence in water-in-oil emulsion droplets," Energy Fuels vol. 24, pp. 1854-1859, 2010.

[21] D. Tarlet, J. Bellettre, M. Tazerout, and C. Rahmouni, "Prediction of micro-explosion delay of emulsified fuel droplets," International Journal of Thermal Sciences vol. 48, pp. 449-460, 2009.

[22] T. Kadota, H. Tanaka, D. Segawa, S. Nakaya, and H. Yamasaki, "Microexplosion of an emulsion droplet during Leidenfrost burning," Proceedings of the Combustion Institute, vol. 31, pp. 2125-2131, 2007.

[23] S. Chung and K. Kim, "An experiment on vaporization and microexplosion of emulsion fuel droplets on a hot surface," 23 Symposium International on Combustion, vol. 23, pp. 1431-1435, 1991.

[24] K. Tsao and C. Wang, "Puffing and microexplosion phenomena of water emulsion fuels," SAE Technical Paper, 1986.

[25] C. Wang and C. Law, "Microexplosion of fuel droplets under high pressure," Combustion and Flame, vol. 59, pp. 53-62, 1985.

[26] C. Law, C. Lee, and N. Srinivasan, "Combustion characteristics of water-in-oil emulsion droplets," Combustion and Flame, vol. 37, pp. 125-143, 1980.

[27] W. Fu, et al., "There is no micro-explosion in the diesel engines fueled with emulsified fuel," Chinese Science Bulletin, vol. 51, pp. 1261-1265, 2006.

[28] D. Ogunkoya, S. Li, O. Rojas, and T. Fang, "Performance, combustion, and emissions in a diesel engine operated with fuel-in-water emulsions based on lignin," Applied Energy, vol. 154, pp. 851-861, 2015.

[29] A. Muhsin, H. Noge, H. Abdul, and W. Jazair, "An overview of utilizing water-in-diesel emulsion fuel in diesel engine and its potential research study," Journal of the Energy Institute vol. 87, pp. 1-16, 2014.

[30] Y. Li, S. Hou, and W. Sheu, "Investigation on boiler efficiency and pollutant emissions of water/heavy oil emulsions using edge-tone resonant homogenizer," Fuel vol. 119, pp. 240-251, 2014.

[31] M. Huo, S. Lin, H. Liu, and C. Lee, "Study on the spray and combustion characteristics of water-emulsified diesel," Fuel vol. 123, pp. 218-229, 2014.

[32] H. Watanabe, T. Harada, Y. Matsushita, H. Aoki, and T. Miura, "The characteristics of puffing of the carbonated emulsified fuel," International Journal of Heat and Mass Transfer vol. 52 pp. 3676-3684, 2009.

[33] E. Mura, C. Josset, K. Loubar, G. Huchet, and J. Bellettre, "Effect of dispersed water droplets in microexplosion phenomenon for water in oil emulsion," Atomization and sprays, vol. 20, pp. 791-799, 2010.

[34] J. Gong and W. Fu, "A study on the effect of more volatile fuel on evaporation and ignition for emulsified oil," Fuel vol. 80, pp. 437-445, 2001.

[35] A. Belkadi, A. Montillet, and J. Bellettre, "Biofuel emulsifier using high velocity impinging flows and singularities in micro-channels," presented at the ASME 2016 Internal Combustion Fall Technical Conference (ICEF2016), Greenville, USA, 2016. 